\title{
A CONFORMAÇÃO DO MERCADO EDITORIAL BRASILEIRO A PARTIR DAS ÚLTIMAS DÉCADAS DO SÉCULO XX E ANOS INICIAIS DO SÉCULO XXI: O CASO DO GRUPO ABRIL ${ }^{1}$
}

\author{
Iara Augusta da Silva ${ }^{2}$
}

\section{RESUMO}

$\mathrm{O}$ artigo visa debater a questão do mercado editorial nas esferas mundial e nacional na contemporaneidade, com destaque ao Grupo Abril. Na primeira parte do estudo, realizou-se uma análise do mercado editorial, em geral, buscando explicar a sua conformação no movimento da sociedade capitalista em seu estágio monopolista. Na segunda, procedeu-se uma discussão sobre a constituição histórica e a organização do Grupo Abril, tendo em vista a posição de destaque que ele ocupa no âmbito do mercado editorial brasileiro, em especial no ramo dos livros didáticos. Como procedimento metodológico realizou-se a análise de Relatórios (2008 a 2013) publicados no sítio oficial dos Grupos Editoriais investigados, de dados estatísticos sobre o movimento do mercado editorial e da produção acadêmica pertinente, visando compreender a natureza histórica da indústria editorial. No Brasil, como em outras partes do mundo, o processo de formação de grandes conglomerados no setor da indústria gráfica tem sido aprofundado e acelerado nas últimas décadas. No caso especial dos grupos editorais, a pesquisa revelou o interesse crescente de empresas de outras regiões do mundo em estabelecer negócios no território brasileiro, por meio de aquisições e fusões. Palavras-chave: Oligopólios editoriais; Capitalismo monopolista; Grupo Abril.

\section{THE CONFORMATION OF BRAZILIAN PUBLISHING MARKET FROM THE LAST DECADES OF THE TWENTIETH CENTURY AND EARLY YEARS OF THE XXI CENTURY: THE CASE OF ABRIL GROUP}

\begin{abstract}
The paper aims to discuss the issue of publishing market in the global and national spheres of the contemporaneity, highlighting the Abril Group. In the first part of the study, it was conducted an analysis about the publishing market, in general, seeking to explain its conformation in the movement of capitalist society in its monopoly stage. In the second, we proceeded a discussion about the historical constitution and the organization of Abril Group, considering the prominent position that it occupies in the Brazilian publishing market, in particular regarding textbooks. As a methodological procedure, it was held the analysis of Reports (2008-2013) that were published on the official website of the surveyed Publishing Groups, statistical data about the movement of the publishing market and the relevant academic literature, aiming to understand the historical nature of the publishing industry. In Brazil, as in other parts of the world, the process of formation of large conglomerates in the printing industry sector has been deepened and accelerated in recent decades. In the special case of the editorial groups, the survey revealed the growing interest on companies of other regions around the world in establishing business in Brazil, through acquisitions and mergers.
\end{abstract}

Keywords: Editorial oligopolies; Monopoly capitalism; Abril Group. 


\section{Introdução}

Este texto analisa a questão do mercado editorial em âmbito nacional e mundial, nas últimas décadas do século XX e anos iniciais do século XXI, dando destaque especial ao Grupo Abril. Inicialmente, apresenta-se um panorama geral do mercado editorial, procurando ressaltar os processos de expansão e de concentração (fusões e aquisições) em escala global que são próprios da organização da sociedade capitalista na contemporaneidade. Em sequência, foi priorizado o estudo da constituição histórica e da organização do Grupo Abril considerando que, ao lado do Grupo Saraiva e da FTD, trata-se de uma empresa que exerce grande influência no mercado editorial brasileiro na atualidade, principalmente quando se refere ao setor de livros didáticos.

Para desenvolver o estudo, foram realizadas, principalmente, leituras de relatórios da administração e demonstrações financeiras dos últimos anos, disponibilizados no sítio oficial dos Grupos Editoriais investigados. Além desses documentos, recorreu-se, ainda, a obras produzidas por autores que desenvolvem pesquisas direcionadas à indústria gráfica e ao mercado editorial (HALLEWELL, 1985; EARP e KORNIS, 2005; SCHIFFRIN, 2006; BORGES, 2009); obras de fundamentos teóricos (MARX e ENGELS, 1990; MÉSZÁROS, 2009; BRAVERMAN, 1987; ALVES, 2001); dados estatísticos sobre o mercado editorial mundial e brasileiro, dentre outros.

O mercado editorial contemporâneo, segundo a abordagem teórico-metodológica adotada, precisa ser analisado levando-se em conta o movimento da sociedade capitalista, em seu estágio monopolista. $\mathrm{O}$ avanço do sistema capitalista em escala mundial, que gerou uma massa significativa de riqueza que circula no mundo sob o gerenciamento dos bancos, não ocorreu por acaso. Foi certamente resultado do processo histórico de lutas entre as classes que compõem o tecido social. Marx e Engels afirmam com propriedade que:
A história de toda sociedade até hoje é a história de lutas de classes. Homem livre e escravo, patrício e plebeu, barão e servo, mestres e companheiros, numa palavra, opressores e oprimidos, sempre estiveram em constante oposição uns com os outros, envolvidos numa luta ininterrupta, ora disfarçada, ora aberta, que terminou sempre ou com uma transformação revolucionária de toda a sociedade, ou com o declínio comum das classes em luta (MARX e ENGELS, 1990, p. 66).

A moderna sociedade burguesa, originada dos escombros da sociedade feudal, conforme Marx e Engels, não eliminou os conflitos existentes entre as classes, pelo contrário, criou "novas condições de opressão, novas formas de luta em lugar das antigas" (MARX e ENGELS, 1990, p. 67). Paulatinamente a sociedade como um todo vai se dividindo em duas grandes classes com interesses opostos: a burguesia e o proletariado. São basicamente estas duas classes que travam uma luta renhida em tempos de capitalismo dito globalizado.

A globalização das relações capitalistas, tão ressaltada por muitos estudiosos da academia contemporânea, coloca-se como um fato que não pode ser negado, não apenas na atualidade como querem alguns, mas desde as origens do capitalismo. Assim, apesar da singularidade de cada região ou país, um traço comum une todos os povos: as leis do capitalismo são inexoráveis, elas envolvem tudo e todos. Ianni explica de forma clara a atual etapa do processo de globalização com as seguintes palavras:

Na base da globalização está o desenvolvimento extensivo e intensivo do capitalismo no mundo. Em todos os lugares expandem-se as forças 
produtivas, compreendendo o capital, a tecnologia, a força de trabalho, a divisão do trabalho social, o mercado, o planejamento e outras. Dinamizam-se as atividades produtivas, os mercados, as associações de empresas, a formação de conglomerados, as teias inter e intracorporações. A concentração e a centralização do capital tanto envolvem a reinversão contínua dos ganhos como a absorção continuada de capitais alheios, próximos e distantes. A atividade industrial deixa de estar concentrada em alguns países dominantes ou metropolitanos, e estende-se a outros países e continentes, independentemente dos imperialismos, blocos geopolíticos; ou recriando uns e outros em diferentes modalidades. As transnacionais planejam, tecem, realizam e desenvolvem as suas atividades por sobre fronteiras e regimes políticos, além das diversidades culturais e civilizatórias. Generalizam-se e intensificam-se as articulações e as tensões entre as mais diversas formas de organização social e técnica da produção material e espiritual (IANNI, 1997, p. 37).

O Brasil não poderia ser diferente, configura-se no século XXI como um país mergulhado no movimento do capitalismo em sua fase monopolista e global, que determina todas as relações sociais, econômicas, políticas e educacionais. Seria ingenuidade acreditar, por exemplo, que o país estaria "blindado", como dizem os arautos da economia política liberal, quanto aos efeitos devastadores da crise econômica atual, exaustivamente noticiada nos meios de comunicação de massa. As instituições bancárias da Europa, dos Estados Unidos, da América Latina a cada dia entram em colapso, sendo necessário que o Estado faça altos investimentos para socorrê-las, com a intenção de retardar a falência do sistema de produção em vigor. A desaceleração da economia e as altas taxas de desempregos em escala mundial são apontadas também como indícios de novo ciclo de crise.

Como se percebe pelas discussões acadêmicas, evidências concretas indicam que o momento atual é de acirramento dos conflitos que permeiam as relações sociais determinadas pelo modo de produção capitalista. É nesse cenário histórico que se analisa o processo de conformação do mercado editorial em âmbito mundial e no Brasil, como um dos segmentos da indústria gráfica, nas últimas décadas.

\section{Um panorama geral do mercado editorial no mundo e no Brasil}

Embora não se pretenda esgotar o assunto, neste artigo procura-se desenvolver um estudo sobre a conformação do mercado editorial mundial e brasileiro, nas últimas décadas. A análise é feita com o apoio de documentos e pesquisas produzidas por economistas e outros profissionais, vinculados ao Banco Nacional de Desenvolvimento Econômico e Social (BNDES), documentos dos Institutos de Economia da UFRJ e da UNICAMP (Projeto PIB), a obra de Earp e Korns (2005), publicada pelo BNDES, o livro de Hallewell (1985), a obra de Borges (2009), entre outros. Os dados sobre o mercado editorial brasileiro, fornecidos pela Associação Brasileira da Indústria Gráfica (ABIGRAF) e pela Câmara Brasileira do Livro (CBL) foram, também, utilizados na efetivação do estudo. Outra fonte de informação são os sítios oficiais das empresas na internet. Esses sítios disponibilizam informações, dados e relatórios administrativos e financeiros que auxiliam na compreensão do alto grau de complexidade que alcançou a organização, o funcionamento e a administração dos grupos de mídias nos tempos atuais.

O mercado editorial mundial e do Brasil já, há algum tempo, vem passando por mudanças substanciais que tendem a acompanhar o movimento de configuração da sociedade capitalista na contemporaneidade. Todos os autores estudados são incisivos em afirmar que, dentre as principais mudanças que vem ocorrendo neste setor da indústria gráfica, está o processo acelerado de concentração de editoras e redes de livrarias, resultante 
de fusões e aquisições efetivadas a todo o momento e em todos os quadrantes do universo. Como decorrência, o que se verifica é a presença de um número cada vez menor de empresas monopolizando o mercado e a forte presença do capital internacional no segmento gráficoeditorial.

As pequenas empresas, criadas e administradas por grupos familiares, em outros tempos tão comuns, mas que ainda sobrevivem apesar dos percalços, representam um quantitativo cada vez mais reduzido ou mesmo tendem a desaparecer do cenário social. No entanto, a tendência que predomina, hoje, em todos os países é, sem dúvida, a formação de grandes conglomerados midiáticos constituídos de canais de televisão, emissoras de rádio, empresas na internet, como também de seus "braços editoriais" (livros, revistas, jornais). Essas corporações funcionam, de fato, como grandes impérios multinacionais do ramo da indústria da comunicação.

Muniz Jr. faz uma reflexão sobre a dinâmica do setor editorial e assinala em seu texto, O grito dos pequenos, que:

Hoje, é impossível pensar na dinâmica do setor editorial, em todo o mundo, sem levar em conta os movimentos que aproximam capital financeiro e capital produtivo, e a produção de conteúdos em diversas mídias, de modo integrado ou ao menos interconectado. Embora alguns autores destaquem a baixa rentabilidade das editoras em comparação com as empresas audiovisuais, por exemplo, o fato é que os grandes conglomerados midiáticos do mundo (Bertelsmann, Disney, Mondadori, Time Warner, Planeta, Viacom, entre outras) possuem seus "braços editoriais" (MUNIZ JR, 2010, p. 9).

Assim, como se afirmou anteriormente, o processo de constituição do mercado editorial acompanha o movimento geral de organização da sociedade em uma determinada época histórica. É necessário entender que a formação dos grandes conglomerados midiáticos, como ocorre também em outros setores da produção, é uma das estratégias do capital para continuar se reproduzindo e gerando lucros para os donos das empresas.

Os pesquisadores, quando analisam o mercado editorial em esfera mundial, são unânimes em ressaltar a posição de destaque ocupada pelos Estados Unidos no campo da indústria gráfica, em geral, e no segmento editorial em particular. Países da Europa como Inglaterra (Reino Unido), Alemanha, França, Espanha, são, igualmente, colocados como possuidores de um mercado de livros de peso e influentes no acelerado processo de internacionalização das empresas do ramo da mídia. É necessário registrar que, mais recentemente, o mercado asiático (Japão, China e Coreias) vem ganhando espaço, incluindo suas empresas no cenário mundial da indústria editorial, em consequência do crescente poder de suas economias e do aumento no número de leitores.

A expansão em escala mundial dos poderosos grupos de mídia constituídos por meio do processo da concentração acentuada do capital e a busca incansável pela diversificação de atividades com a intenção de aumentar os ganhos, fez com que o "mercado editorial se tornasse parte de uma pequena fatia da indústria de comunicação de massa" (BORGES, 2009 , p. 23). Os processos cada vez mais constantes de aquisições e fusões, a princípio difíceis de serem compreendidos, dadas as múltiplas facetas e abrangência do mercado financeiro capitalista em seu estágio atual de desenvolvimento, acabaram por dar origem aos grandes conglomerados de mídia em âmbito global.

As informações expostas no quadro 1 demonstram a situação do mercado editorial em esfera mundial e no Brasil, tendo em vista a posição ocupada pelos grandes grupos midiáticos a partir do faturamento obtido no ano de 2011. 
Nota-se, inicialmente, que as dez maiores corporações do ramo editorial estão concentradas em países da Europa e nos Estados Unidos. A liderança no mercado global, em 2011, ficou com a empresa Pearson do Reino Unido, que obteve um faturamento de aproximadamente oito bilhões e meio de dólares. A Pearson, fundada em 1844 durante a Revolução Industrial, é considerada, hoje, o maior grupo do mercado editorial mundial voltado para o ramo dos livros didáticos, estando presente em mais de cinquenta países (BORGES, 2009, p. 24-25).

Quadro 1 - Ranking Global do Mercado Editorial - 2011

Em US\$ Milhões

\begin{tabular}{|l|l|l|l|}
\hline $\begin{array}{l}\text { Ranking } \\
2011\end{array}$ & $\begin{array}{l}\text { Grupo ou Divisão } \\
\text { (Publishing Company) }\end{array}$ & País sede & Receita (2011) \\
\hline $1^{\mathbf{o}}$ & Pearson & Reino Unido & 8.411 \\
\hline $2^{\mathbf{o}}$ & Reed Elsevier & Reino Unido/Holanda/EUA & 5.686 \\
\hline $3^{\text {o }}$ & Thomson Reuters & EUA/Canadá & 5.435 \\
\hline $4^{\mathbf{o}}$ & Wolters Kluwer & Holanda & 4.360 \\
\hline $5^{\mathbf{o}}$ & Hachette Livre & França & 2.649 \\
\hline $6^{\circ}$ & Planeta & Espanha & 2.304 \\
\hline $7^{\circ}$ & McGraw-Hill Education & EUA & 2.292 \\
\hline $8^{\mathbf{o}}$ & Bertelsmann & Alemanha & 2.274 \\
\hline $9^{\circ}$ & Holtzbrinck & Alemanha & 1.952 \\
\hline $10^{\circ}$ & Scholastic (corp.) & EUA & 1.906 \\
\hline $24^{\circ}$ & Grupo Santillana & Espanha & 936 \\
\hline $40^{\circ}$ & Abril Educação & Brasil & $\mathbf{4 1 1}$ \\
\hline $50^{\circ}$ & Saraiva & Brasil & $\mathbf{2 6 7}$ \\
\hline $52^{\circ}$ & Editora FTD & Brasil & $\mathbf{2 2 6}$ \\
\hline
\end{tabular}

Fonte: Publishers Weekley/EUA. Adaptação da autora.

No mesmo ano (2011), os Estados Unidos ${ }^{3}$ também tiveram importante participação neste ranking, pois quatro das dez editoras que mais faturaram estão naquele país, alcançando uma receita de mais de quinze bilhões de dólares. Das empresas localizadas na Europa, duas dentre as dez editoras que mais faturam no mundo têm sede na Alemanha, ultrapassando a soma de quatro bilhões de dólares no ano em estudo. O Grupo alemão Bertelsmann, nas últimas décadas do século XX, tem se mantido no topo do ranking das empresas que mais faturam neste setor do mercado, na Alemanha.

$\mathrm{Na}$ Espanha, conforme o quadro 1, um grupo editorial chama atenção pela posição que ele ocupa nesse ranking - a Planeta - sexto lugar e uma receita de mais de dois bilhões de dólares (BORGES, 2009, p. 49-50). Aumentando o destaque da Espanha no concorrido mercado do livro, aparece o Grupo Santillana que, merece atenção, por ter se estabelecido no Brasil e demais países da América Latina, no decorrer do século XX e início do século XXI, com grande força na produção de livros didáticos. Não se pode deixar de colocar, principalmente, que o Grupo Santillana, braço editorial do poderoso conglomerado de mídias espanhol Prisa, passou a administrar a Editora Moderna, comprada por R\$ 150 milhões de reais pelos donos desse conglomerado. A Moderna, é importante que se diga, sempre foi uma das empresas brasileiras campeã em vendas de obras literárias e didáticas para o Governo Federal.

Cassiano (2007) desenvolveu um estudo longo e detalhado com o objetivo de esclarecer, entre outras questões relacionadas ao mercado editorial e ao Programa Nacional do Livro Didático (PNLD), no período de 1985 a 2007, os fatores que geraram interesse de grupos espanhóis, em particular do Santillana, na expansão dos negócios em terras 
brasileiras e em outros países da América Latina, como México, Argentina, Chile, Equador, Bolívia, Costa Rica e El Salvador. Cassiano afirma, de maneira clara, que o mercado latinoamericano de livros didáticos, incrementado pelo desenvolvimento de programas nacionais na esfera estatal e financiados com recursos dos organismos multilaterais, na década de 1990, representou um grande filão para os grupos editoriais internacionais, em especial os editores espanhóis, os quais exerceram (e ainda exercem), segundo a autora, o papel de protagonistas.

Voltando ao estudo do quadro 1, é preciso esclarecer que foi necessário prolongar a tabela do ranking mundial das dez maiores companhias midiáticas em escala mundial até o $52^{\circ}$ lugar, para visualizar a situação das empresas editoriais com sede no Brasil, melhores posicionadas nesse mercado global. Em $40^{\circ}$ lugar, encontra-se a Abril Educação, a melhor colocada no ramo da indústria gráfica, com um faturamento, no ano de 2011, em torno de US\$ 411 milhões. Seguem-se a ela o grupo Saraiva (50 lugar), com uma receita de 267 milhões de dólares, e a Editora FTD (52 lugar), com um saldo anual de 226 milhões de dólares.

Como se pode constatar claramente, observando os números do quadro 1 , o desempenho financeiro das maiores editoras brasileiras situa-se em patamar bem inferior, quando se considera o panorama da produção editorial mundial. Em outros termos, enquanto as corporações estadunidenses e europeias arrecadam anualmente para seus cofres bilhões de dólares, as brasileiras ficam na casa dos milhões de dólares (KOTH, 2005, p. 39).

É significativo lembrar que a Abril Educação, a Saraiva e a FTD, as empresas brasileiras melhor posicionadas no ranking dos maiores grupos editoriais do mundo, exposto no quadro 1, têm se destacado fortemente, ao longo das últimas décadas, no segmento dos livros didáticos. Ao concentrar uma grande parcela desse mercado, elas têm conseguido aumentar os seus lucros, já há muitos anos seguidos, com a inclusão, no Programa Nacional do Livro Didático, de um número volumoso de obras dedicadas aos alunos da educação básica das escolas públicas.

\section{O Grupo Abril e o domínio do mercado dos livros didáticos}

No Brasil, como vem ocorrendo em outras partes do mundo, de forma intensa nas últimas décadas, também foram se constituindo grandes conglomerados de mídia na esteira do desenvolvimento da sociedade capitalista. É o caso do Grupo Abril, considerado como um dos maiores da América Latina. Esse grupo atua no mercado por meio de uma gama de atividades tão variadas que, às vezes, torna-se uma tarefa difícil mapear o seu campo de abrangência. Ao visitar o sítio da empresa se vê estampado um universo grande de áreas que envolvem serviços e produtos em geral. O Grupo Abril incorporou ao seu complexo industrial um conjunto de empresas (marcas) voltadas para os mais diversos ramos do entretenimento, da comunicação, da cultura e da educação: revistas, livros, televisão, internet (Abril.com), telefonia, marketing, mídia em geral, eventos culturais e premiações (Prêmio Victor Civita: Professor Nota 10), viagens, sustentabilidade (Planeta Sustentável).

O Grupo Abril deu início às suas atividades no Brasil, no ano de 1950 com a fundação da Editora Abril Ltda. e da Sociedade Anônima Impressora Brasileira (SAIB), instaladas em São Paulo. O nome Abril, escolhido pela família Civita - originária da Itália - de acordo com o próprio sítio da empresa, deveu-se ao fato de que no mês de abril, na Europa, tem início a primavera. Já a árvore verde, símbolo emblemático do grupo, representa a "fertilidade, prosperidade e otimismo". Com esse espírito os membros da família Civita e seus sócios deram a arrancada em seus empreendimentos investindo, a princípio, no setor de revistas. A primeira publicação foi, justamente, uma revistinha de história em quadrinhos - O Pato Donald - produzida em parceria com o conglomerado Walt Disney, dos EUA. A esta 
publicação seguiram-se, dentre tantas outras revistas, as voltadas ao público feminino (Capricho/1952 e Cláudia/1961); ao mundo da moda (Manequim/1959); aos motoristas (Quatro Rodas/1960); ao público em geral (Veja/1968); aos admiradores do esporte (Placar/1970); aos professores da educação básica (Nova Escola/1986); aos apreciadores do mundo das celebridades (Caras/1995).

Cabral (2005), em sua tese de doutorado, realiza uma análise detalhada sobre a formação e desenvolvimento do Grupo Abril, desde as suas origens na década de 1950 até os anos iniciais de 2000. Em seu estudo, a autora esclarece o processo de internacionalização da corporação, ressaltando a presença dos parceiros de outros países e a abertura para o capital estrangeiro. A parceria com o conglomerado Walt Disney foi (e continua até hoje) a primeira feita entre a Editora Abril e um grupo internacional. Outras parcerias serão efetivas durante a caminhada da empresa em busca de espaço no concorrido mercado editorial mundial.

Os empreendimentos da Editora Abril, relacionados ao mercado de livros, segundo Hallewell (1985, p. 568), teve início com uma edição ilustrada da Bíblia Sagrada, intitulada A Bíblia mais bela do mundo, em 1965, quando o Brasil vivia tempos de plena ditadura militar. Essa obra foi publicada em forma de fascículos quinzenais e comercializada numa rede de bancas de jornal que se colocou à disposição da empresa, totalizando 150.000 exemplares vendidos, por fascículo.

Hallewell (1985, p. 568-569) esclarece ainda que, dando continuidade a esse projeto editorial, a Abril diversificou bastante os temas incluídos na publicação em forma de fascículos (coleções), como por exemplo: filosofia (Os pensadores), em 1974, com uma venda de 100.000 exemplares por semana; economia (Os economistas), em 1982; música (Grandes compositores da música universal, em 48 fascículos, Grandes óperas, 24 fascículos e Música popular brasileira, em 60 fascículos), em 1972; ciência (Os cientistas), também em 1972. Para cuidar da publicação dessas coleções, a Editora criou uma divisão: a Abril Cultural, mais tarde substituída pela Nova Cultural.

É relevante destacar que as coleções como Os economistas e Os pensadores, lançadas naquela época e relançadas em anos posteriores, publicaram textos clássicos da literatura universal, como os de Adam Smith, Marx, Friedman, Platão, Bacon, Maquiavel, apenas para citar alguns nomes que compunham as referidas coleções. A introdução e tradução das obras são assinadas por autores renomados, como José Artur Giannotti, Leandro Konder, Paul Singer, Jacob Gorender, entre outros. Essa iniciativa, com certeza, prestou um importante serviço à difusão do conhecimento científico. Os textos clássicos chegaram às mãos dos leitores brasileiros por meio de coleções da Editora Abril vendidas em bancas de jornal com preços acessíveis.

Ainda hoje fazem parte da produção do Grupo Abril as coleções vendidas nas bancas e por intermédio do sítio da empresa (Abril coleções). Para atender aos estudantes do ensino médio das escolas do país, a empresa, desde 2010, vem disponibilizando a coleção Curso Preparatório ENEM: guia do estudante, em 20 volumes. Além dessas, outras podem ser adquiridas, como Cozinha do Mundo, Grandes Mestres (da pintura), Copa do Mundo FIFA, Clássicos Disney para Ler e Ouvir, Clique a Clique (curso de informática). As coleções da Editora Abril seguem um formato que, na maioria das vezes, incluem material impresso e material de mídia, o que se torna um atrativo a mais para conquistar o público consumidor.

Em sua trajetória inicial, na busca de espaço mais sólido no mercado editorial nacional e internacional do livro, a Abril desenvolveu outras iniciativas. Uma delas, bem conhecida do público leitor, foi a criação, em 1973, do Círculo do Livro, com o objetivo de constituir uma rede de sócios interessados em comprar, com regularidade, pelo menos uma vez ao mês, a partir de um leque variado de títulos, obras oferecidas por meio de uma revista 
promocional e distribuída de forma gratuita. Os livros eram entregues em domicílio, por meio dos Correios.

As atividades do Círculo do Livro foram realizadas em conjunto com o grupo alemão Bertelsmann, que já possuía larga experiência com essa forma de comerciar livros. Embora, no início, o negócio não tenha sido bem sucedido, depois de algum tempo gerou um faturamento expressivo em razão do crescimento do número de sócios espalhados por todo o país. As vendas de livro, em 1982, "foram de 5.000.000 de exemplares, totalizando 17.000.000 na primeira década do Clube" (HALLEWELL, 1985, p. 574).

Segundo Hallewell, paralelamente a esses primeiros empreendimentos desenvolvidos a Abril ingressou, também, na parte "tradicional do comércio livreiro". Na década de 1980 foi criada uma divisão específica com a finalidade de promover a comercialização de seus produtos em livrarias e supermercados de todas as regiões do país. E, então, pouco depois, a empresa fundou a sua própria rede de livrarias (a Tchau!), com o propósito de resolver a "crônica falta de livrarias no Brasil" (HALLEWELL, 1985, p. 574).

Os canais de venda do Grupo Abril cresceram consideravelmente nos últimos tempos, com destaque para a sua cadeia de lojas online. Hoje, tudo que é produzido por ela e pelas empresas parceiras pode ser comprado por meio do comércio eletrônico (Lojas Abril.com). A facilidade de busca e acesso às mercadorias oferecidas da maneira mais atraente possível conquistam os clientes. Os inúmeros sítios, que compõem a rede de lojas virtuais, propiciam um crescimento considerável da receita total da corporação, assim como contribui para a satisfação das necessidades de consumo das pessoas criadas pelo próprio mercado capitalista.

Para intensificar o processo de publicação e venda de seus produtos, o Grupo Abril desenvolveu e aprimorou o seu próprio sistema de impressão gráfica, logística e distribuição. Com um parque gráfico próprio extremamente moderno e um sistema ágil de distribuição, a empresa consegue, com pontualidade, entregar, em domicílio, milhões de exemplares de revistas aos assinantes de todas as regiões do país.

$\mathrm{Na}$ década de 1980, já com um império editorial montado ${ }^{4}$, a Abril passou por transformações significativas em sua organização interna, por conta de um impasse ocorrido entre os herdeiros da família Civita, que culminou com a cisão do conglomerado. Roberto Civita, o filho mais velho, ficou com as revistas e o nome editora Abril. O Grupo Abril, como se conhece na atualidade, é constituído pelas empresas de Roberto Civita (Presidente do Conselho de Administração e Editor $)^{5}$, que diversificou e ampliou bastante as atividades do grupo, transformando-o em uma companhia de mídia, com a participação de acionistas internacionais e de capital proveniente de outras regiões do mundo.

Em relação aos parceiros de negócios, o Grupo Abril, ao longo de sua trajetória, tem se associado a empresas situadas em outros países, como também, daquelas de origem nacional. Os objetivos das associações são: a) consolidar a posição de liderança no mercado de livros e de outros produtos midiáticos; b) enfrentar momentos de crise financeira e queda no faturamento; c) diversificar fontes de receitas; d) aumentar e racionalizar os lucros; e) ampliar o leque de produtos que compõe o portfolio da empresa; e, f) dominar segmentos do mercado considerados promissores (Relatórios do Grupo Abril, 2008 a 2013). O processo de parceria tem se desenvolvido por meio de incorporações, controle de parte do capital da empresa parceira, criação de subsidiárias, venda de parte das ações da própria corporação, dentre outras.

No final da década de 1990 e início do século XXI, o Grupo Abril passou por grave turbulência financeira - endividamento e queda no faturamento - que atingiu não apenas ele próprio, como também o mercado editorial brasileiro como um todo, em decorrência de continuadas crises que vêm deteriorando a economia capitalista em todas as regiões do 
planeta. Para enfrentar essa situação, o Grupo Abril intensificou a abertura para o capital internacional, com duas transações financeiras que, de maneira relevante, alterou a composição acionária da companhia.

A primeira transação foi efetivada em 2004, quando o Fundo de Investimento Capital Group, de origem norte-americana, passou a deter 13,8\% da empresa Civita, em troca de R \$ 150 milhões, que seriam usados para pagar as dívidas e financiar novos investimentos. A outra transação foi concluída dois anos mais tarde (2006) com a Naspers, uma empresa de mídia sul-africana fundada em 1915. Esta empresa adquiriu 30\% das ações do Grupo Abril no valor de R $\$ 868$ milhões ${ }^{6}$. A Naspers, de acordo com o Relatório de Demonstrações Financeiras de 2006 e 2007 da Editora Abril é

Uma multinacional que atua em dois segmentos principais: mídia eletrônica e impressa. Na área eletrônica, as operações envolvem televisão paga, internet e atividades tecnológicas relacionadas, que constituem a MIH Holdings. O grupo possui operações de TV Paga e internet na Grécia, Chipre, Tailândia, Rússia, Índia e China, além da África do Sul, onde concentra a maior parte de suas operações. A área impressa envolve a impressão e distribuição de jornais e revista, além de operações com internet da Media24 Digital. O grupo é composto ainda pela Via Afrika e pela Educor, voltadas ao desenvolvimento de vários produtos e sistemas ligados à educação (GRUPO ABRIL. EDITORA ABRIL S.A., 2008, p. 6).

Percebe-se, pela descrição do perfil da multinacional, que a Naspers desenvolve um conjunto de operações no campo da mídia em geral (eletrônica e impressa) em diferentes continentes e plataformas, como também possui um setor específico voltado para a educação que se assemelha às desenvolvidas pelo Grupo Abril. Isso significa, de certa forma, uma "bagagem de técnicas, modelos e estratégias que pode ser transferida, mesmo que parcialmente, aos veículos do Grupo Abril" (PEREZ, 2008, P. 7). Fora isso, a Naspers é uma companhia que tem como tática básica expandir os seus negócios para os mais variados quadrantes do mundo (China, Índia, Rússia, Tailândia... e, o Brasil) por meio de aquisições de empresas bem posicionadas no mercado de mídias e com possibilidades de crescimento do seu capital.

A organização corporativa do Grupo Abril, após os anos que sucederam à sua fundação, em 1950, mostra-se complexa e diferenciada, visto que ele foi se desenvolvendo em conformidade com as transformações sofridas pelo mercado editorial internacional e brasileiro em cada momento histórico.

Atualmente, a estrutura do Grupo Abril, pelo que se pode depreender das informações disponibilizadas no site e nos Relatórios de Administração e Balanço Financeiro da empresa, é constituída por três segmentos, os quais, embora exerçam suas operações de forma independente (com parceiros e organização diferenciada), fazem parte de um núcleo central denominado "Abrilpar": holding da família Civita, gerido por um Conselho de Administração que define as políticas estratégicas (administrativas e financeiras) a serem colocadas em prática pela corporação. Os três segmentos do Grupo Abril são: a Abril Educação S.A., a Abril S.A. e a Fundação Victor Civita.

A educação constitui uma das áreas que o Grupo Abril tem investido fortemente nos últimos anos. Para dar consequência aos seus propósitos, em 2007 foi criada a Abril Educação S.A., que passou a constituir um dos braços importante da corporação. Desde 2010, a Abril Educação S.A. atua de forma separada da Abril S.A. devido às modificações feitas na organização societária da companhia. Em 2011, ela abriu o capital na BMF\&BOVESPA, com a finalidade de concretizar "ambições de crescimento". Esse 
empreendimento na Bolsa de Valores, segundo informações do Relatório da Abril Educação, apesar do momento "desafiador do mercado de capitais", gerou para seus cofres R \$ 371,1 milhões, dos quais $67 \%$ foram reservados para "aquisições estratégicas" (GRUPO ABRIL. ABRIL EDUCAÇÃO S.A., 2012, p. 1-2).

Dessa maneira, fica patente que, na área da indústria editorial, a formação de monopólios e as transações na esfera do mercado financeiro são tendências do capital que, desde os anos de 1980 se aprofundam na sociedade contemporânea em geral. A perspectiva desse processo segue no sentido de buscar novas metamorfoses, na tentativa de ganhar novo fôlego e continuar o curso da sua reprodução sociometabólica, como diz Mészáros (2009) em seus escritos.

Conforme o sítio da empresa, a marca Abril Educação nasceu com o objetivo de "ser influente e atuante na melhoria da qualidade da educação oferecida no país" (sítio do Grupo Abril) e, tem como meta a educação básica e pré-universitária no Brasil. A sua estratégia para competir no mercado se baseia em "atender escolas públicas e privadas com uma plataforma completa de produtos, conteúdo, serviços e tecnologias de qualidade integrados, capazes de gerar alta fidelização de clientes e baixas taxas de inadimplências" (GRUPO ABRIL. ABRIL EDUCAÇÃO S.A., 2012, p. 4). A companhia desenvolve suas operações com o foco centrado em três linhas de negócios consideradas essenciais, por meio de marcas com tradição no mercado editorial brasileiro: a) editoras (Ática e Scipione); b) sistemas de ensino; c) escolas e cursos preparatórios.

Quanto ao segmento das editoras, em 2004, o Grupo Abril, mesmo antes da criação da Companhia Abril Educação, já havia dado um passo fundamental e de maneira efetiva em direção ao campo da produção e venda de livros infantis, juvenis e didáticos, obras de referência (dicionários e atlas), quando concretizou a compra integral das editoras Ática e Scipione $^{7}$. Essas duas editoras, que sempre ocuparam um lugar de destaque no mercado editorial brasileiro, já tinham acumulado uma larga experiência, principalmente, no setor de produção de livros didáticos e paradidáticos. Por meio dessa estratégia, a companhia conseguiu, com sucesso, penetrar na área mercadológica altamente lucrativa dos livros didáticos. Como se sabe, as editoras Ática e Scipione, desde longa data, têm sido responsáveis pela venda de um volume significativo de coleções didáticas para o Programa Nacional de Livros Didáticos (PNLD).

Dessa forma, a Abril Educação, após a incorporação das editoras Ática e Scipione, ao deixar pouca margem à concorrência das outras empresas do ramo, vem monopolizando o mercado editorial brasileiro ao estabelecer recordes de vendas de livros didáticos para o Governo Federal. O Relatório da Abril Educação informa que:

Em relação ao foco no desenvolvimento dos negócios existentes, cumpre ressaltar o recorde das editoras Ática e Scipione, na entrega de 50,4 milhões de livros didáticos no Programa Nacional do Livro Didático (PNLD) do governo federal, que compra e distribui livros para todas as escolas públicas de nível básico do país. O resultado das editoras Ática e Scipione foi significativamente superior ao de seus principais concorrentes. Nossos livros didáticos chegaram a cerca de 126 mil escolas onde estão matriculados aproximadamente 30 milhões de alunos (GRUPO ABRIL. ABRIL EDUCAÇÃO S.A., 2012, p. 2).

O trecho do Relatório citado acima ressalta o número expressivo de obras didáticas vendidas pela Ática e pela Scipione (50,4 milhões de reais), editoras de propriedade da Abril Educação, para o Programa Nacional do Livro Didático (PNLD), com vistas a atender os estudantes da educação básica. A quantidade expressiva de escolas (126 mil) existentes 
atualmente e de alunos matriculados (30 milhões), como coloca o excerto, representa, obviamente, uma razão concreta para o Grupo Abril continuar investindo fortemente no ramo dos didáticos.

Quadro 2 - Linhas de Negócios da Abril Educação S.A. - 2007 a 2012

\begin{tabular}{|c|c|c|c|}
\hline $\begin{array}{l}\text { Linhas de } \\
\text { negócios }\end{array}$ & Empresas & Composição societária & Atividades, materiais e serviços \\
\hline \multirow{5}{*}{$\begin{array}{l}\text { Sistema de } \\
\text { Ensino }\end{array}$} & SER & $\begin{array}{l}\text { Criado pelo Grupo } \\
\text { Abril em } 2007\end{array}$ & $\begin{array}{l}\text { Material didático, conteúdo } \\
\text { multimídia, proposta pedagógica, } \\
\text { capacitação de professores, assessoria } \\
\text { pedagógica, planejamento de } \\
\text { campanha de matrículas, orientações } \\
\text { para os pais.* }\end{array}$ \\
\hline & Anglo & Aquisição em 2010 & $\begin{array}{l}\text { Material didático, conteúdo } \\
\text { multimídia, proposta pedagógica (...). }\end{array}$ \\
\hline & $\mathrm{pH}$ & Aquisição em 2011 & $\begin{array}{l}\text { Material didático, conteúdo } \\
\text { multimídia, proposta pedagógica (...). }\end{array}$ \\
\hline & Máxi & Aquisição em 2011 & $\begin{array}{l}\text { Material didático, conteúdo } \\
\text { multimídia, proposta pedagógica (...). }\end{array}$ \\
\hline & GEO & Aquisição em 2012 & $\begin{array}{l}\text { Material didático, conteúdo } \\
\text { multimídia, proposta pedagógica (...). }\end{array}$ \\
\hline \multirow{4}{*}{ Curso } & Anglo & Aquisição em 2010 & $\begin{array}{l}\text { Educação infantil, Ensino } \\
\text { Fundamental, Ensino Médio e Pré- } \\
\text { Vestibular }\end{array}$ \\
\hline & $\begin{array}{l}\text { Anglo } \\
\text { (SIGA) }\end{array}$ & Aquisição em 2010 & Preparação para concursos públicos \\
\hline & $\mathrm{pH}$ & Aquisição em 2011 & $\begin{array}{l}\text { Preparação para o vestibular (Pré- } \\
\text { Vestibular) }\end{array}$ \\
\hline & Livemocha & $\begin{array}{l}\text { Aquisição em } 2011 \\
\text { (5,9\% da Livemocha) }\end{array}$ & Ensino de idiomas online \\
\hline \multirow{5}{*}{ Escola } & Anglo & Aquisição em 2010 & Ensino Médio \\
\hline & $\mathrm{pH}$ & Aquisição em 2011 & Ensino Fundamental e Ensino Médio \\
\hline & ETB & Aquisição em 2011 & Ensino Técnico \\
\hline & Satélite & $\begin{array}{l}\text { Aquisição em } 2012 \\
\text { (51\% da Satélite) }\end{array}$ & $\begin{array}{l}\text { Elaboração, produção e coordenação } \\
\text { de cursos telepresenciais, serviços de } \\
\text { ensino a distância }\end{array}$ \\
\hline & Red Balloon & Aquisição em 2012 & $\begin{array}{l}\text { Ensino de inglês para crianças e } \\
\text { adolescentes }\end{array}$ \\
\hline
\end{tabular}

Fonte: Relatórios e sítio da Abril Educação (2012).

* Conforme sítio da Abril Educação S.A. (2012).

Sob o "guarda-chuva" da Abril Educação S.A. encontram-se, além das operações realizadas pelas editoras, outras linhas de negócios ligadas ao campo educacional, tais como os sistemas de ensino, as escolas e os cursos preparatórios, que visam oferecer um conjunto variado de atividades, materiais e serviços às escolas particulares e públicas de todo o país.

O quadro 2 apresenta as linhas de negócios que eram desenvolvidas pela Abril Educação S.A. no ano de 2012, além do ramo das editoras, destacando as empresas (marcas) que compõem cada um desses campos de atuação, as formas da sua participação (inclusão) 
na companhia, como ainda especifica as atividades e serviços oferecidos e os materiais didáticos produzidos.

Percebe-se, na coluna que explicita as linhas de negócios, a presença de três grupos distintos de empresas, quais sejam: cinco Sistemas de Ensino, quatro Cursos e cinco Escolas. Os Sistemas de Ensino, conforme o sítio do GrupoAbril, desenvolvem o mesmo conjunto de operações como pode ser observado no quadro 2, ainda que eles tenham propósitos metodológicos e materiais didáticos diferenciados . Os Cursos oferecem preparação para o vestibular, para concursos públicos e, também, direcionam-se para o ensino de idiomas.

Quanto às escolas compradas ou controladas pela Abril Educação, nota-se que uma delas - a pH - dedica-se à oferta da educação básica, enquanto a escola (Escola Técnica do Brasil/ETB) está voltada para o oferecimento de ensino técnico e a Escola Anglo dedica-se a ofertar o ensino médio. Cabe ressaltar que as Escolas Red Balloon e Satélite, como é possível constatar no quadro 2, são as duas empresas mais recentemente agregadas (2012) ao "portfólio de negócios" da Abril Educação. A Escola Red Balloon oferece ensino de inglês para crianças e jovens. A Satélite trata-se de uma escola que disponibiliza serviços na modalidade a distância. Com esse novo empreendimento, a companhia passa a atuar em um setor da educação bastante promissor, pois tem a oportunidade de atingir milhares de estudantes em todo o Brasil.

Considera-se relevante salientar que, segundo as informações do quadro 2, a Abril Educação S.A. não mediu esforços para diversificar os negócios nos dois últimos anos, de maneira a abocanhar fatias do mercado voltadas para o campo da educação brasileira. Verifica-se, claramente, que no período de 2010 a 2012, por meio de aquisições (total ou parcial), a companhia incorporou empresas de reconhecida tradição e eficiência na área de ensino, como é o caso do Grupo Anglo que, desde a sua criação, há mais de 60 anos, tem vendido os seus produtos e serviços para milhares de instituições escolares localizadas nas diversas regiões do país.

É de se questionar o que motiva as empresas editoriais a lançar mão da estratégia mercadológica de diversificação das suas atividades, em especial, no campo educacional ${ }^{8}$. Conforme os Relatórios da Abril Educação, de 2011 e 2012, a busca pela ampliação continuada do raio de atuação da empresa nas mais diversas áreas e formas de oferta de educação é uma estratégia para aumentar seu crescimento e potencializar a diversificação de suas receitas. Além disso, a ampliação do leque de operações educacionais pela corporação, demonstrada pelas informações do quadro 2, é explicada pela necessidade de reduzir os efeitos da forte sazonalidade que caracteriza o processo de comercialização entre as editoras Ática e Scipione e o Governo Federal brasileiro. Isto é, as vendas de livros didáticos para atender o PNLD concentram-se prioritariamente no primeiro e no quarto trimestre do ano (GRUPO ABRIL. ABRIL EDUCAÇÃO S.A., 2012, p. 5). Sendo assim, é necessário complementar o faturamento anual com outros negócios.

No que se refere ao faturamento da Abril Educação no ano de 2011, os Relatórios de Demonstrações Financeiras e de Administração estudados indicam que a companhia acumulou melhoria de receitas e rentabilidade em todos os setores de atuação, fruto do "foco no crescimento orgânico, na integração dos negócios adquiridos e na implementação de sinergias" (GRUPO ABRIL. ABRIL EDUCAÇÃO S.A., 2011, p. 1). A receita líquida consolidada da empresa, naquele ano, atingiu um total de $\mathrm{R} \$ 772,1$ milhões, enquanto em 2010 foi de $\mathrm{R} \$ 512,12$ de milhões, o que significou um crescimento de mais de $50 \%$ (GRUPO ABRIL. ABRIL EDUCAÇÃO S.A., 2012, p. 1 e 6). Esse faturamento total da Abril Educação é resultado das receitas líquidas geradas por suas principais linhas de negócios, discutidas anteriormente. 
A tabela 1 permite visualizar o detalhamento dos dados financeiros relativos à participação de cada linha de negócio na composição da receita líquida total da Abril Educação, no exercício de 2011.

Constata-se que as editoras Ática e Scipione apresentaram um desempenho financeiro bem expressivo em relação ao das outras atividades desenvolvidas pela empresa. Elas contribuíram com $\mathrm{R} \$ 506,3$ milhões, correspondendo a $66 \%$ do faturamento total. Isso comprova o peso que representa as vendas de livros didáticos e paradidáticos para o mercado privado e, principalmente, para o Governo Federal, via o PNLD.

Tabela 1 - Receita Líquida da Abril Educação S.A. por Linha de Negócio - 2011*

\begin{tabular}{l|l|l|l|l}
\hline $\begin{array}{l}\text { Linhas de } \\
\text { Negócios }\end{array}$ & $\begin{array}{l}\text { Ática e Scipione } \\
\text { (Editoras) }\end{array}$ & $\begin{array}{l}\text { Anglo } \\
\text { (Curso e Sistema } \\
\text { de Ensino) }\end{array}$ & $\begin{array}{l}\text { pH } \\
\text { (Escola e Sistema } \\
\text { de Ensino) }\end{array}$ & $\begin{array}{l}\text { SER } \\
\text { (Sistema de } \\
\text { Ensino) }\end{array}$ \\
\hline $\begin{array}{l}\text { Receita } \\
\text { líquida } \\
\%\end{array}$ & 506,3 & 163,9 & 60,1 & 37,5 \\
\hline
\end{tabular}

Fonte: Relatório da Abril Educação (2011). Elaboração da autora.

* A análise dos dados deve ser feita levando em conta a data de aquisição das empresas ocorridas em diferentes meses dos anos de 2010 e de 2011.

Em seguida, tem-se o Anglo (Curso Preparatório e Sistema de Ensino), com uma participação significativa de $21 \%$ no rendimento de 2011 , ou seja, uma receita de R $\$ 163,9$ milhões. De acordo com os Relatórios da Abril Educação, o Anglo com sua marca reconhecida no mercado editorial brasileiro, além de ter agregado experiência e novas práticas às sua operações, passou a contribuir de maneira efetiva no seu faturamento anual.

Em relação à participação das outras duas linhas de negócios na composição do faturamento da Abril Educação, pH (Curso e Sistema de Ensino) e SER (Sistema de Ensino), verifica-se um percentual bem menor, de $8 \%$ ( $\mathrm{R} \$ 60,1$ milhões) e 5\% (R $\$ 37,5$ milhões) respectivamente. É preciso esclarecer, porém, que a rede de escolas $\mathrm{pH}$, passou a contribuir com as receitas da Abril Educação a partir de abril de 2011, quando foi comprada por ela (GRUPO ABRIL. ABRIL EDUCAÇÃO S.A., 2011, p. 5).

Quanto à companhia Abril S.A. ${ }^{9}$, outro segmento do Grupo Abril, ela desenvolve negócios voltados para o campo da comunicação em geral. $\mathrm{O}$ foco da empresa se concentra nas seguintes atividades: a) editorial e gráfica (edição, impressão, distribuição e vendas de revistas, anuários, guias e publicações técnicas); b) internet (provedor de conteúdo, acesso, venda de publicidade e produtos); c) redes de televisão (TVA e a MTV); d) distribuição e logística (operação de entrega dos produtos); e, f) serviços (organização e promoção de eventos, comercialização de propaganda e publicidade).

Merece destaque dentre as atividades desenvolvidas pela Abril S.A. a divisão responsável pela edição de revistas dirigidas para os mais variados campos de interesse (economia, política, lazer, esporte, cultura em geral, moda, mundo das celebridades) e, também aos estágios de vida do leitor (infantil, jovem e adulto). São bastante conhecidas e lidas, dada a grande circulação em todo o território brasileiro, muitas revistas publicadas pela Editora Abril como, por exemplo, a revista Veja, que chega semanalmente à residência de milhares de assinantes além de serem vendidas, de forma avulsa, diretamente nas bancas de jornal do país. Com larga experiência na área de produção de revistas, a Editora Abril há mais de sessenta anos vem consolidando a sua posição de liderança nesse setor do mercado editorial brasileiro. 
A Editora Abril S.A., segundo os relatórios da empresa, conta com um diferencial em relação aos seus concorrentes, visto que possui um sistema próprio de produção, impressão, logística e distribuição de suas revistas. Diante disso, a companhia vem acumulando, ao longo dos tempos, um crescimento significativo em seu faturamento, tendo em conta o número significativo de revistas vendidas e os novos títulos lançados a cada ano. Em 2010, a Editora Abril obteve, com suas operações mercadológicas, uma renda líquida de 2,1 bilhões de reais, representando um crescimento de 7,2\% em comparação a 2009. Nesse ano, o número de exemplares vendidos alcançou um total considerável de 177,3 milhões, a partir de 54 títulos comercializados (GRUPO ABRIL. EDITORA ABRIL S.A., 2011, p. 3, 4 e 7$)$.

A Fundação Victor Civita, criada em 1985 por aquele que lhe deu nome, constitui o terceiro segmento ou divisão do Grupo Abril. A missão da Fundação é "contribuir para a melhoria da qualidade da Educação Básica no Brasil, produzindo conteúdo que auxilie na capacitação e valorização de professores e gestores e influencie políticas públicas" (Sítio da Fundação Victor Civita). Para cumprir sua missão de cunho educacional, a Fundação Civita utiliza como veículo basilar as revistas Nova Escola e Gestão Escolar e o livro Estudos e Pesquisas Educacionais, especialmente produzidos para serem lidos pelos educadores e gestores. A Fundação promove, ainda, uma atividade de premiação ao professor da Educação Básica (Prêmio Professor Nota 10), com a intenção de incentivar o trabalho do docente e divulgar práticas pedagógicas exitosas desenvolvidas nas escolas brasileiras.

\section{Algumas considerações finais}

No Brasil, como em outras partes do mundo, o processo de formação de grandes conglomerados no setor da indústria gráfica tem sido acelerado e aprofundado nas últimas décadas. No caso especial dos grupos de editoras, a pesquisa revelou a tendência de internacionalização, com a crescente entrada de capital externo nos últimos tempos. Foi possível perceber, com o estudo mais detido do Grupo Abril, que o mercado editorial em âmbito mundial e no território brasileiro vem passando por significativas transformações, principalmente pela formação de grandes corporações de mídias, das quais fazem parte as editoras e as redes de livrarias. O movimento de globalização, que acompanha o desenvolvimento do capitalismo desde os seus primórdios até a contemporaneidade ${ }^{10}$ é refletido, também, na conformação dos grupos editoriais, que procuram expandir seus negócios para várias regiões do planeta, em busca de novos mercados e de novas fontes de lucros.

Dessa maneira, no caso específico do Brasil, o setor de livros tem sido objeto de interesse de empresas de outras regiões do mundo já há algum tempo. A Santillana, com sede na Espanha, pode ser citada como exemplo elucidativo de um grupo editorial que percebeu o potencial representado pelo mercado brasileiro de livros, em especial, o ramo dos didáticos. Não foi por acaso que essa companhia multinacional comprou, em 2001, a Moderna, editora que ao longo dos anos vem ocupando lugar destacado dentre aquelas que mais vendem obras didáticas para o Governo Federal. O número expressivo de estudantes que frequenta a escola pública de educação básica e é contemplado com obras didáticas, adquiridas e distribuídas gratuitamente pelo Estado, por meio do Programa Nacional do Livro Didático, representa de fato um incentivo considerável à aplicação de capital por parte de corporações internacionais.

De acordo com Cassiano (2007, p. 95-100), o segmento de livros didáticos, um mercado altamente promissor não apenas no Brasil, como em outros países da América Latina, é considerado um forte atrativo para que muitos grupos editoriais da Europa e dos 
Estados Unidos estabeleçam suas subsidiárias ou adquiram empresas bem posicionadas no mercado deste continente.

É pertinente colocar que, nem sempre é possível delinear de maneira precisa o processo de internacionalização das empresas do ramo das mídias no país. As negociações entre as corporações envolvidas, na maioria das vezes, são longas, pois abrange um sistema intrincado de composição do capital a ser investido, da forma de efetivar a associação entre as organizações empresariais, tais como joint venture, consórcios, fusão, aquisição, incorporação, aliança estratégica (TRICHES, 1996, p. 14-31), bem como as estratégias utilizadas para atuar no mercado e os selos a serem criados ou incorporados, com o propósito de potencializar os lucros da companhia que emergirá desse processo de mundialização do capital.

As empresas de mídias instaladas no Brasil, no período de 1971 a 2011, têm na sua linha editorial um conjunto diversificado de publicações como obras de referência, livros infanto-juvenis, livros técnicos e científicos, clássicos da literatura, livros de ficção e de não ficção e, principalmente, livros didáticos. É interessante registrar que as grandes corporações, atualmente, apresentam em seu portfólio o livro na versão impressa e o livro na versão digitalizada (o denominado $e$-book).

Finalmente, deve-se acrescentar que os estudos realizados apontam a forte intenção por parte dos grupos editoriais brasileiros em aperfeiçoar e intensificar a produção de livros eletrônicos (digitais), o que parece ser o segmento mais promissor do mercado editorial em todo o mundo, nos dias de hoje. Recentemente (2012), circulou na mídia a informação que os donos da rede de livrarias Saraiva, uma das mais destacadas do Brasil, estariam analisando as possibilidades da venda dessas empresas para a Amazon.com, poderoso império do comércio varejista eletrônico dos Estados Unidos. Como se sabe, depois de anos de estudos e negociações, em dezembro de 2012, a Amazon.com abriu sua primeira loja virtual em território brasileiro.

\section{Referências}

ALVES, Gilberto Luiz. A produção da escola pública contemporânea. Campo Grande, MS: Ed. da UFMS; Campinas, SP: Autores Associados, 2001.

BORGES, Bárbara. Um novo cenário para o negócio do livro. São Paulo: COM-ARTE, 2009.

BRAVERMAN, Harry. Trabalho e capital monopolista: a degradação do trabalho no século XX. Rio de Janeiro: Guanabara, 1987.

CABRAL, Eula Dantas Taveira. Internacionalização da mídia brasileira: estudo de caso do Grupo Abril. Tese de doutorado. São Bernardo do Campo, SP: UMESP, 2005.

CASSIANO, Célia Cristina de Figueiredo. O mercado do livro didático no Brasil: da criação do Programa Nacional do Livro Didático (PNLD) à entrada do capital internacional espanhol (1985-2007). Tese de Doutorado. São Paulo: PUC/SP, 2007.

CASTANHO, Sérgio. Globalização, redefinição do estado nacional e seus impactos. In: LOMBARDI, José Claudinei (Org.). Globalização, pós-modernidade e educação. Campinas, SP: Autores Associados: HISTEDBR; Caçador, SC: UnC, 2003.

EARP, Fábio Sá; KORNIS, George. A economia da cadeia produtiva do livro. Rio de Janeiro: BNDES, 2005. 
EPSTEIN, Jason. O negócio do livro: passado, presente e futuro no mercado editorial. São Paulo: Record, 2002.

GORINI, Ana Paula Fontenelle; BRANCO, Carlos Eduardo Castello. Panorama do setor editorial brasileiro. Rio de Janeiro: BNDES Setorial, n.11, março de 2000. Disponível: http://www.bndes.gov.br. Acesso em 01/junho/2011.

GRUPO ABRIL. Editora Abril S.A. Relatório de Demonstrações Financeiras referentes aos exercícios findos em 31 de dezembro de 2007 e de 2006 e Parecer dos Auditores Independentes. 2008. Disponível em: http://www.grupoabril.com.br/arquivo/balanco. Acesso: 4/08/2012.

GRUPO ABRIL. Editora Abril S.A. e Empresas Controladas. Relatório de demonstrações financeiras referentes ao exercício findo em 31 de dezembro de 2010 e Relatório dos Auditores Independentes. 2011. Disponível em: http://www.grupoabril.com.br/arquivo/EDA. Acesso: 24/agosto/2012.

GRUPO ABRIL. Abril S.A. e empresas controladas. Relatório de Demonstrações financeiras consolidadas referentes ao exercício findo em 31 de dezembro de 2010 e Relatório dos Auditores Independentes. 2011. Disponível em http://www.grupoabril.com.br. Acesso: 24/agosto/2012.

GRUPO ABRIL. Abril Educação S.A. Relatório de Administração da Abril Educação: segundo semestre de 2011. 2011. Disponível em: http://www.abrileducacao.com.br. Acesso: 24/agosto/2012.

GRUPO ABRIL. Abril Educação S.A. Relatório de Demonstrações Financeiras em 31 de dezembro de 2011 e Relatório dos Auditores Independentes. 2012. Disponível em: http://www.abrileducacao.com.br. Acesso: 24/agosto/2012.

GRUPO ABRIL. Relatório de Desempenho e Sustentabilidade 2013 do Grupo Abril: uma nova perspectiva. 2013. Disponível em: http://grupoabril1.abrilm.com.br/relatorio. Acesso: 20/maio/2014.

HALLEWELL, Laurence. O livro no Brasil: sua história. São Paulo: T. A. Queiroz: Ed. da Universidade de São Paulo, 1985.

KORTH, Leonardo Cláudio. As transformações na indústria editorial de livros no Brasil e os desafios para as empresas brasileiras. Dissertação de Mestrado. Rio de Janeiro: EBAPE/CFAP/FGV, 2005.

MARX, Karl; ENGELS, Friedrich. Manifesto do partido comunista. Petrópolis, RJ: Vozes, 1990.

MÉSZÁROS, Istiván. Para além do capital: rumo a uma teoria de transição. São Paulo: Boitempo, 2009.

MUNIZ JR., José de Souza. O grito dos pequenos: independência editorial e bibliodiversidade no Brasil e na Argentina. São Paulo: Balão Editorial, 2010. Disponível: http://www.balaoeditorial.com.br/download. Acesso em 11/maio/2012.

PADILHA, Maria Fernanda Freire Gatto; LIMA, João Policarpo Rodrigues. Sistema produtivo: perspectivas do investimento em cultura. Documento Setorial (2009). Projeto PIB/UFRJ/UNICAMP. Disponível: http://www.projetopib.org/documentos. Acesso em 18/janeiro/2012. 
PEREZ, Bruno Manuel Mandelli. A Abril e a Naspers: um estudo de caso do capital estrangeiro na mídia brasileira. Monografia (Trabalho de Conclusão do Curso de Comunicação Social - habilitação em Jornalismo). São Paulo: USP, 2008.

SAAB, William George Lopes; GIMENEZ, Luiz Carlos Perez. Cadeia de comercialização de livros: situação atual e propostas para desenvolvimento (1999). Disponível: http://www.bndes.gov.br. Acesso em 01/junho/2011.

SCHIFFRIN, André. O negócio dos livros: como as grandes corporações decidem o que você lê. Rio de Janeiro: Casa da Palavra, 2006.

SÍTIO GRUPO ABRIL (http://grupoabril.com.br, 2012).

SÍTIO DA FUNDAÇÃO VICTOR CIVITA (http://www.fvc.org.br, 2012).

TRICHES, Divanildo. Fusões, aquisições e outras formas de associações entre empresas no Brasil. Revista de Administração. São Paulo, v. 31, n. 1, janeiro/março de 1996. Disponível em http://www.rausp.usp.br/busca/artigo. Acesso em 13/04/2013.

\footnotetext{
${ }^{1}$ O presente artigo é parte da Tese de Doutorado em Educação defendida em 2013, sob a orientação da Prof ${ }^{a}$ $\mathrm{Dr}^{\mathrm{a}}$ Silvia Helena Andrade de Brito, na Universidade Federal de Mato Grosso do Sul (UFMS).

${ }^{2}$ Doutora em Educação pela Universidade Federal de Mato Grosso do Sul. Professora do quadro da Secretaria de Estado de Educação de Mato Grosso do Sul.

${ }^{3}$ Epstein (2002) e Schiffrin (2006) relatam, a partir de experiências, como editores, a constituição de grandes conglomerados no mercado editorial norte-americano (1930 a 1990).

${ }^{4}$ De acordo com Hallewell (1985, p. 574), em 1971, "a Abril já era a terceira maior empresa editorial brasileira (depois das Listas Telefônicas Brasileiras e da Companhia Melhoramentos de São Paulo), com um lucro de $28 \%$ sobre seu capital de 42,5 milhões de cruzeiros. Em 1980 - ano particularmente desfavorável para a indústria editorial - ela obteve $17,5 \%$ sobre um capital de 1.534 milhões, sem contar as companhias subsidiárias, como a Abril Cultural".

${ }^{5} \mathrm{Em} 2013$, com a morte de Roberto Civita, o Grupo Abril passou por novas reestruturações na sua governança corporativa. Atualmente, o Presidente do Conselho de Administração do Grupo Abril é Giancarlo Francesco Civita, filho de Roberto Civita (GRUPO ABRIL, 2013, p. 9).

${ }^{6}$ Segundo Perez (2008, p. 51): "Para controlar 30\% das ações da Abril, limite estabelecido constitucionalmente ao capital estrangeiro, a Naspers comprou a totalidade das ações pertencentes ao Capital Group, também estrangeiro. Os 13,8\% das ações da Abril que estavam em nome da Capital Group foram vendidas pelo fundo por $\mathrm{R} \$ 363$ milhões - mais que o dobro do valor pago na aquisição das mesmas, dois anos antes".

${ }^{7}$ O Grupo Abril adquiriu parcialmente a Ática e a Scipone em 1999 por US\$ 100 milhões, numa parceria com o Grupo francês Vivendi. Em 2004, porém, com a compra da parte que cabia à Vivendi, o Gurpo Abril tornouse o único dono da Ática e da Scipone. Hoje, essa duas empresas lideram a venda de livros didáticos no Brasil, com cerca de $30 \%$ a $35 \%$ do mercado (BORGES, 2009, p. 127).

${ }^{8} \mathrm{Na}$ Mensagem da Administração da Abril Educação aos seus acionistas pode-se ler: "Estamos confiantes que a estratégia de foco na oferta de soluções para escolas de ensino básico através de uma plataforma completa e de qualidade de produtos, conteúdos, serviços e tecnologias é acertada, e que a executaremos com eficácia e eficiência, visando à construção de valor para nossos acionistas". (GRUPO ABRIL. ABRIL EDUCAÇÃO S.A., 2011, p. 4).

${ }^{9}$ A Abril S.A., ("Companhia") "é uma sociedade anônima com sede em São Paulo, Estado de São Paulo. Sua controladora é a Ativic S.A. e, em conjunto com as sociedades controladas, compartilha as estruturas e os custos corporativos, gerenciais e operacionais" para empreender os seus diversos negócios (GRUPO ABRIL. ABRIL S.A., 2011, p. 9).

${ }^{10}$ Sérgio Castanho (2003, p. 16-22) considera que a globalização é uma tendência que acompanha todo o capitalismo, desde o seu nascedouro, tendência essa que faz parte da lógica interna desse modo de produção.
}

Recebido: fevereiro-15

Aprovado: março-15 